\title{
Chitosan/Silica Composite Membrane: Adsorption of Lead(II) Ion from Aqueous Solution
}

\author{
N. Rosdi ${ }^{\mathrm{a}}$, M. N. M. Sokri ${ }^{\mathrm{a}, \mathrm{b}^{*}}$, N. M. Rashid ${ }^{\mathrm{b}}$, M. S. Che Chik ${ }^{\mathrm{b}}$, M. S. Musa ${ }^{\mathrm{b}}$ \\ aAdvanced Membrane Technology Centre (AMTEC), Universiti Teknologi Malaysia, \\ 81310 UTM Johor Bahru, Johor, Malaysia \\ ${ }^{\mathrm{b}}$ School of Chemical and Energy Engineering, Faculty of Engineering, Universiti \\ Teknologi Malaysia, 81310 UTM Johor Bahru, Johor, Malaysia
}

Submitted: 4/10/2018. Revised edition: 15/11/2018. Accepted: 20/11/2018. Available online: 5/12/2018

\begin{abstract}
Chitosan membrane has the potential to separate lead(II) ions from aqueous solution. However, the kind of membrane has a drawback due to the low structural properties. Thus, this study investigates the role of silica in improving chitosan-based flat sheet membrane for removal of lead(II) ions from aqueous solution. The functional groups and structural morphologies were characterized using Fourier Transform Infrared-Attenuated Total Reflectance (FTIR-ATR) spectrometer and Scanning Electron Microscope (SEM), respectively. The membrane performance in terms of adsorption study was conducted at different $\mathrm{pHs}$ and initial concentration of lead(II) solution. The FTIR-ATR spectrum showed the existence of new absorption peak of chitosan/silica membrane. SEM images revealted the presence of microvoids on the cross-section of the chitosan/silica membrane whereas pure chitosan membrane possessed dense structure. The adsorption study showed that the composite membrane exhibited higher efficiency of lead(II) removal at optimum $\mathrm{pH}$ of 7.0 which was $89.27 \%$ as compared to $11.50 \%$ of pure chitosan membrane. The amount of lead(II) adsorbed onto the membrane was $57.60 \mathrm{mg} / \mathrm{g}$. Therefore, it indicates the potential use of silica to improve the properties of chitosan membrane for removal of heavy metal from water solution.
\end{abstract}

Keywords: Chitosan, silica, membrane, lead(II), adsorption

\subsection{INTRODUCTION}

The metal-contaminated wastewater still represents a worldwide environmental problem due to the industrialization and technological advances [1]. The lead metals are among the well-known heavy metal that are toxic and carcinogenic [2]. Due to their high solubility, living organisms can easily absorb the heavy metals that entering the eco-system. The accumulation in human body may occur if the amount of metals consumed beyond the limits, either by ingestion or food chain [3]. This will cause serious health problem such as cancer, damage of organ and nervous system, which can disrupt the growth and development of human body [4]. Therefore, it is essential to treat the metalcontaminated wastewater before being discharge to the environment.

There are several techniques that can be implied for removal of lead from water streams but one of the most convenient operations was membrane adsorption [5]. Membrane have its own advantages such as low production cost, easy to handle, high flow rate and possess excellent efficiency for removal of metal ions $[6,7]$.

Previously, researcher used synthetic polymer such as polyacrylonitrile (PAN) and polyethylene terephthalate (PET) for 
membrane fabrication [8]. Recently, natural bio-polymer such as chitosan has gained increasing attention to be used as adsorptive membrane since it contains hydroxyl and amine groups that acts as active sites for adsorption process [9]. However, chitosan membrane have low structural and physical properties which limits their potential use to remove lead metal ions [10].

Rice husk is the agricultural waste that most abundantly found in rice production country. In Malaysia, it is estimated that about 1, 564, 604 tons of rice will be produced in year 2020 [11]. As the production of rice increases, so does the production of rice husk. This circumstance can lead to the space limitation when it disposes to the landfills [12]. In a previous study, Battegazzore et al. [13] found that 80$90 \%$ of silica can be obtained from thermally treated rice husk. Theoretically, silica can interact with hydroxyl and amine groups of chitosan due to the presence of silanol groups [14]. However, in wastewater treatment application, sodium silicate was commonly used as a silica source [15].

Thus, in this study, sodium silicate was synthesized from agricultural waste of rice husk and used in the fabrication of chitosan/silica composite membrane to improve the properties of chitosan membrane. Then, the membranes were characterized by using FTIR-ATR and SEM analysis. Several parameters were investigated in adsorption study of the pure chitosan and chitosan/silica membrane which were $\mathrm{pH}$ effect and initial concentration of the lead(II) solution. The adsorptive performance was further evaluated by Langmuir and Freundlich isotherm model to identify their adsorption behaviour.

\subsection{METHODS}

\subsection{Materials}

Commercial chitosan $\quad(75-85 \%$ deacetylated) with medium molecular weight was purchased from Sigma Aldrich $^{\circledR}$. Rice husks were collected from Kilang Beras Jelapang Selatan (M) Sdn Bhd., Muar, Johor. Acetic acid glacial $(\geq 99.85 \%)$ was obtained from $\mathrm{HmbG}^{\circledR}$ Chemicals. Both, sodium hydroxide $(\mathrm{NaOH}, 99 \%)$ and lead(II) nitrate $\left(\mathrm{Pb}\left(\mathrm{NO}_{3}\right)_{2}, \quad \geq 99.5 \%\right)$ were purchased from QRëC ${ }^{\mathrm{TM}}$.

\subsection{Silica Source Preparation}

Rice husks were incinerated at $600^{\circ} \mathrm{C}$ for $3 \mathrm{~h}$ to produce rice husk ash which was then mixed with $1 \mathrm{M} \mathrm{NaOH}$ solution (molar ratio $\mathrm{Si} / \mathrm{Na}=1$ ). The product was sintered at $800^{\circ} \mathrm{C}$ for $2 \mathrm{~h}$ to produce sodium silicate.

\subsection{Membrane Fabrication}

In this study, membrane preparation consists of pure chitosan and chitosan/silica membrane fabrication.

For chitosan/silica membrane, sodium silicate $(0.2 \mathrm{~g})$ was first dissolved in $50 \mathrm{~mL}$ of $0.1 \mathrm{M}$ acetic acid. $1 \mathrm{~g}$ of chitosan were later added and stirred until it is completely dissolved to obtain homogeneous dope solution, followed by sonication. A yellowish colour solution was then casted onto the clean glass plate and left for at least 24 $\mathrm{h}$ at room temperature to allow the solvent to evaporate. The dried membrane was then immersed in $1 \mathrm{M}$ $\mathrm{NaOH}$ solution and followed by a rinse with distilled water to make it neutral prior to drying at room temperature.

For pure chitosan membrane, similar method was used as chitosan/silica membrane fabrication with the absence of sodium silicate addition. 


\subsection{Characterization}

The chemical composition in rice husk ash obtained from incineration process was examined by using X-ray Fluorescence (XRF), (Bruker, S4Pioneer model). The samples were prepared by press powder method prior to analysis. The physical interactions between chitosan and silica were determined by using Fourier Transform Infrared-Attenuated Total Reflectance Spectrometer (FTIR-ATR), (JASCO, FT/IR-4200IF). The samples were scanning at a wavelength of $400 \mathrm{~cm}^{-1}$ to $4000 \mathrm{~cm}^{-1}$. The surface and crosssectional morphology of the membranes were observed under Scanning Electron Microscopy (SEM), (Hitachi, TM3000 model). All the samples were cut into smaller pieces and sputter with gold prior to observation.

\subsection{Membrane Performance}

The adsorption study of the chitosan/silica membrane on lead removal was conducted at different $\mathrm{pH}$ and initial concentration of lead(II) solution. To each sample, $0.05 \mathrm{~g}$ of pure chitosan and chitosan/silica membrane were used.

For the $\mathrm{pH}$ study, membranes were added into $50 \mathrm{~mL}$ of lead(II) solution $(100 \mathrm{mg} / \mathrm{L})$ at various $\mathrm{pH}(5.0,6.0,7.0$ and 8.0) and agitated for $24 \mathrm{~h}$. The $\mathrm{pH}$ was adjusted by using $0.01 \mathrm{M} \mathrm{HCl}$ and $0.1 \mathrm{M} \mathrm{NaOH}$ solutions. The removal efficiency, $\mathrm{R}$ was calculated by using Equation 1.

The adsorptive performance of the membranes at different initial concentration $(60,80,120,140,160$, $180,200,220$ and $240 \mathrm{mg} / \mathrm{L}$ ) was done with $50 \mathrm{~mL}$ of lead(II) solution at optimum $\mathrm{pH}$. The adsorption capacity, qe was calculated by using Equation 2 .

$$
\begin{aligned}
& R(\%)=\frac{C_{o}-C_{e}}{C_{o}} \times 100 \% \\
& q_{e}\left(\frac{m g}{g}\right)=\frac{\left(C_{o}-C_{e}\right) V}{m}
\end{aligned}
$$

where $C_{o}$ and $C_{e}(\mathrm{mg} / \mathrm{L})$ are initial concentration and equilibrium concentration of metal, respectively; $V$ (L) is the volume of the solution and $m$ (g) is the dry mass of the membrane used.

The adsorption isotherm mechanism of the chitosan/silica membrane for removal of lead(II) metal ions from aqueous solution were evaluated based on the Langmuir and Freundlich isotherm models as described in Equations 3 and 4, respectively.

$$
\begin{aligned}
& \frac{C_{e}}{q_{e}}=\frac{1}{Q_{\max } b}+\frac{C_{e}}{Q_{\max }} \\
& \ln q_{e}=\ln K_{F}+\left(\frac{1}{n}\right) \ln C_{e}
\end{aligned}
$$

where $q_{e}(\mathrm{mg} / \mathrm{g})$ is amount of lead(II) adsorbed onto the membrane; $C_{e}$ $(\mathrm{mg} / \mathrm{L})$ is equilibrium concentration of metal; $Q_{\max }(\mathrm{mg} / \mathrm{g})$ is maximum adsorption capacity; $b$ is Langmuir constant; $K_{F}(\mathrm{mg} / \mathrm{g})$ is Freundlich constant and $1 / n$ is parameter related to adsorption intensity. Throughout the study, equilibrium concentration of the metal for each sample was analysed by using Atomic Adsorption Spectroscopy (AAS), (Shimadzu AAS, AA-7000 model).

\subsection{RESULTS AND DISCUSSION}

\subsection{Characterization}

\subsubsection{XRF Analysis}

White rice husk ash was obtained from the burning process of rice husk at $600^{\circ} \mathrm{C}$. The chemical composition was 


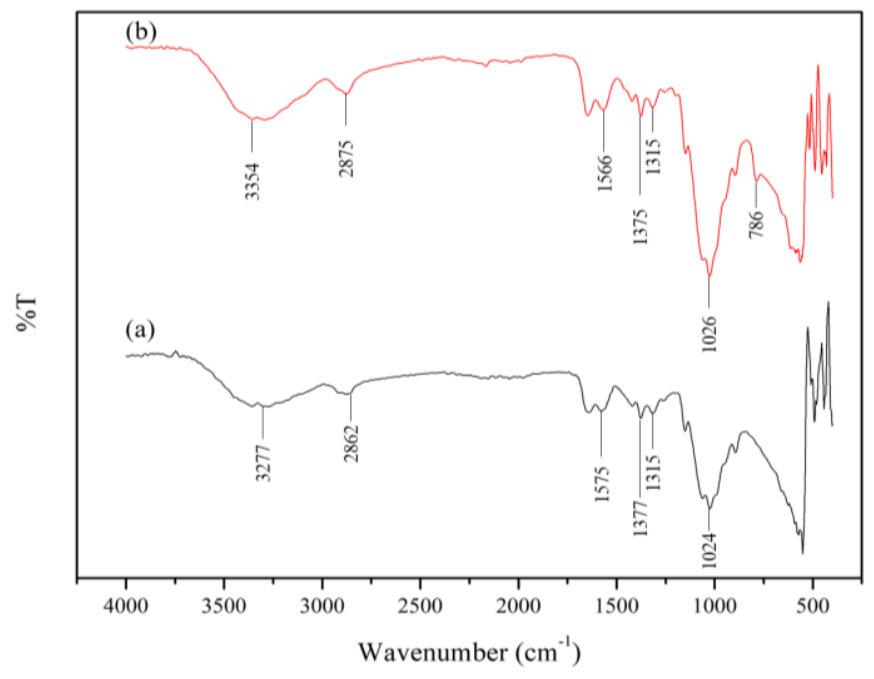

Figure 1 FTIR-ATR image of (a) chitosan membrane (b) chitosan/silica membrane

determined by XRF analysis as shown in Table 1. It specifies that silica, $\mathrm{SiO}_{2}$ act as the major ingredient in the rice husk ash along with other metal oxides such as alumina, ferric oxide, titanium oxide, calcium oxide, magnesium oxide, zinc oxide, manganese(II) oxide, phosphorus pentoxide and others. It was noteworthy to make a good used of agriculture waste to yield silica. Besides, it can solve the environmental problems due to the limitation of waste disposal space.

Table 1 Chemical composition of rice husk

\begin{tabular}{cc}
\hline Element & $\begin{array}{c}\text { Mass Percent } \\
(\boldsymbol{\%})\end{array}$ \\
\hline $\mathrm{SiO}_{2}$ & 87.4 \\
$\mathrm{Al}_{2} \mathrm{O}_{3}$ & 0.5 \\
$\mathrm{Fe}_{2} \mathrm{O}_{3}$ & 0.2 \\
$\mathrm{TiO}_{2}$ & 0.0 \\
$\mathrm{CaO}$ & 1.4 \\
$\mathrm{MgO}$ & 0.6 \\
$\mathrm{~K}_{2} \mathrm{O}$ & 4.1 \\
$\mathrm{ZnO}$ & 0.0 \\
$\mathrm{MnO}$ & 0.2 \\
$\mathrm{P}_{4} \mathrm{O}_{10}$ & 0.5 \\
Others & 5.1 \\
\hline
\end{tabular}

\subsubsection{FTIR-ATR Analysis}

In Figure 1, the spectra showed broad adsorption band at 3277 and $3354 \mathrm{~cm}^{-1}$. It corresponds to the vibration of hydroxyl groups that bonded to carbon atoms and silica atoms [16]. Between wavenumber area of $3500-3100 \mathrm{~cm}^{-1}$, there was stretching vibrations of $\mathrm{N}-\mathrm{H}$ that was overlap with the adsorption band of O-H. Both bands at 2862 and $2875 \mathrm{~cm}^{-1}$ are due to the C-H stretching vibrations [17]. The deformation of N$\mathrm{H}$ bond of amino groups of pure chitosan and chitosan/silica membrane were observed at 1575 and $1566 \mathrm{~cm}^{-1}$, respectively [18]. The peaks at 1377 , 1375 and $1315 \mathrm{~cm}^{-1}$ were observed due to the $\mathrm{C}-\mathrm{H}$ bending vibrations. The band at $1024 \mathrm{~cm}^{-1}$ represents the vibrations of $\mathrm{C}-\mathrm{O}$ of $\mathrm{CH}-\mathrm{OH}$ groups, same as proposed by Mahatmanti et al. [19]. Meanwhile, the appearance of band at $1026 \mathrm{~cm}^{-1}$ and $786 \mathrm{~cm}^{-1}$ correspond to the asymmetric Si-O-Si bond and symmetric Si-O-Si bond of chitosan/silica composite membrane, respectively. Similar results were reported by $\mathrm{He}$ et al. [20]. 

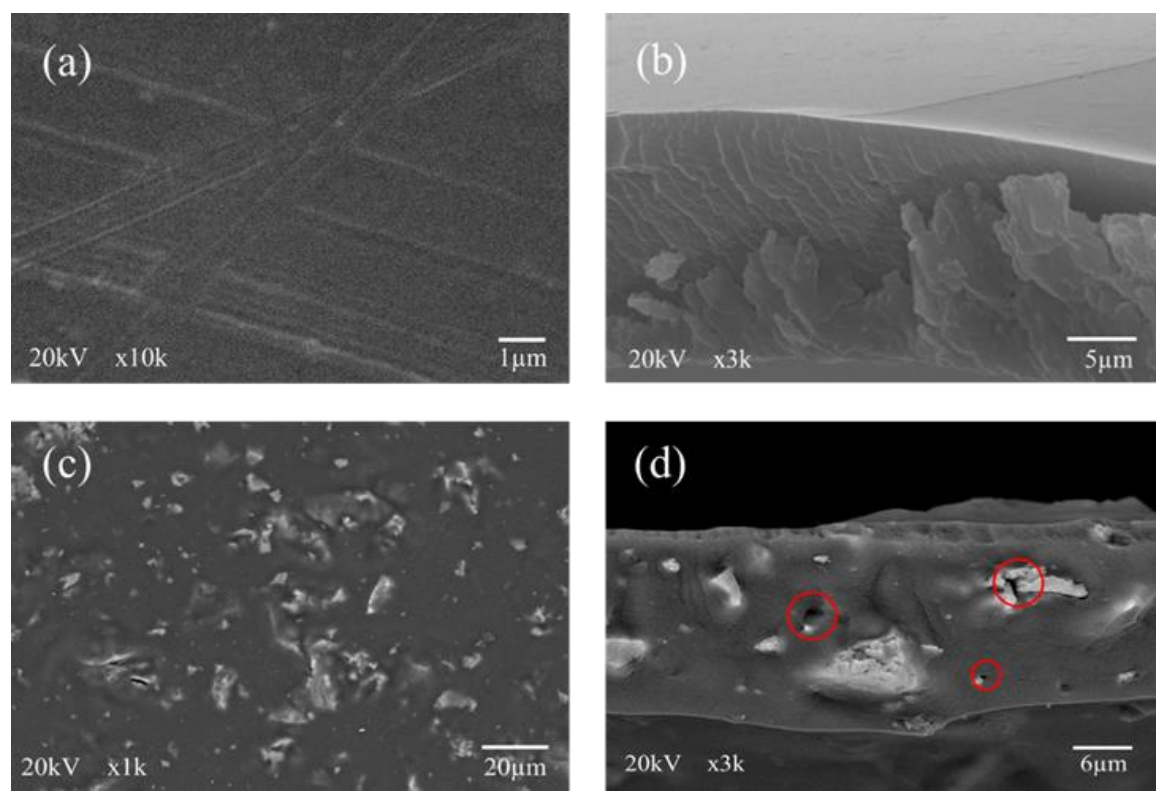

Figure 2 SEM images of (a) surface and (b) cross-section of pure chitosan membrane; (c) surface and (d) cross-section of chitosan/silica composite membrane

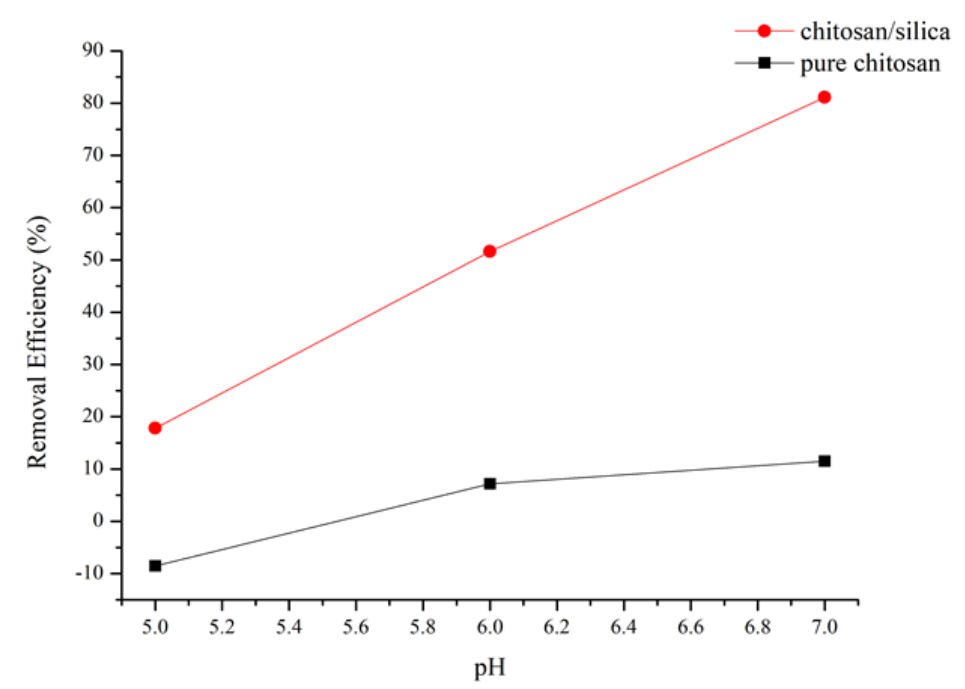

Figure 3 The effect of $\mathrm{pH}$ on the removal of lead(II) from aqueous solution

\subsubsection{SEM Analysis}

The structural morphologies of the membranes are presented in Figure 2. The pure chitosan membrane showed dense cross-sectional structure. This result was supported by Rekik et al. [10] who observed pure chitosan membrane has a uniform, smooth, flat surface and displays a homogeneous structure. However, the surface of the membrane became more rougher after the addition of sodium silicate in chitosan dope solution and some microvoids were presence in inner structure of the membrane which can help in the separation of lead(II) metal ions from aqueous solution. 

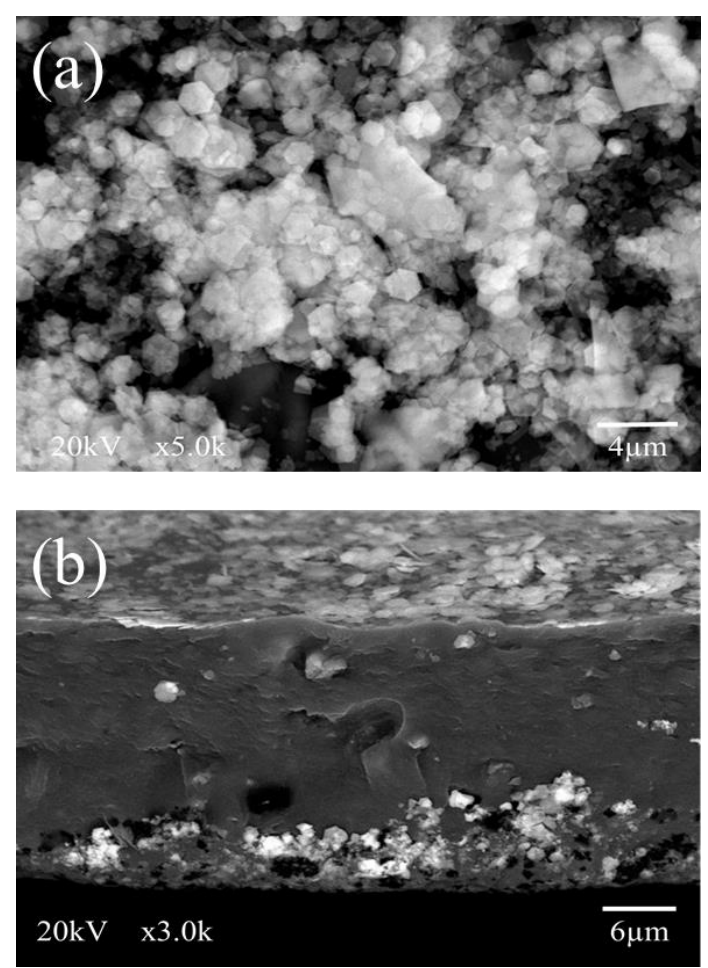

Figure 4 Structural morphologies of (a) surface and (b) cross-section of chitosan/silica membrane after adsorption study at $\mathrm{pH} 7.0$

\subsection{Membrane Performance on Lead(II) Removal from Aqueous Solution}

\subsubsection{Effect of $\mathrm{pH}$}

The $\mathrm{pH}$ effect on the adsorption of lead(II) ion onto pure chitosan and chitosan/silica membrane was presented in Figure 3. As shown in the figure, the adsorption of metal ions increased as the increasing of $\mathrm{pH}$. This finding proved that the adsorption efficiency of lead(II) metal ions was strongly dependent on the $\mathrm{pH}$. In acidic condition, there was counteraction between metal ions, $\mathrm{Pb}^{2+}$ and $\mathrm{H}^{+}$which leading to the low adsorption efficiency of lead(II) metal ions onto the membrane [21]. The optimum $\mathrm{pH}$ was found at $\mathrm{pH} 7.0$ with chitosan/silica composite membrane exhibited $89.27 \%$ of adsorption efficiency. It was slightly higher as compared to pure chitosan membrane which exhibited $11.50 \%$ of removal efficiency of lead(II) metal ions. At pH 8.0, instead of adsorption, chemical precipitation was taking place. This is due to the formation of lead hydroxide ion such as $\mathrm{Pb}_{4}\left(\mathrm{OH}_{4}\right)^{4+}$, $\mathrm{Pb}_{6}\left(\mathrm{OH}_{8}\right)^{4+}$ and $\mathrm{Pb}_{4}\left(\mathrm{OH}_{4}\right)^{2+}$ in basic condition [22]. The adsorption of lead metal ions onto chitosan/silica membrane were further supported with SEM analysis of the membrane after adsorption at $\mathrm{pH}$ 7.0. As seen in Figure 4 , the presence of hexagonal structure on the membrane surface can be observed and some of the lead(II) metal ions were adsorbed onto the microvoids that exists in the cross-section of the membrane. Then, it is further investigated by SEM-EDX mapping as displayed in Table 2. From the data obtained, it is confirmed that the hexagonal structure was lead(II) metal ions with 67.24 wt.\% , besides other elements of the composite membrane which are oxygen, carbon and silicon. 
Table 2 SEM-EDX analysis of chitosan/silica composite membrane after adsorption study $\mathrm{pH} 7.0$

\begin{tabular}{lclll}
\hline Element & AN & Series & $\begin{array}{l}\text { norm. } \\
\text { C } \\
\text { (wt. \%) }\end{array}$ & $\begin{array}{l}\text { Atom. } \\
\text { C } \\
\text { (at. \%) }\end{array}$ \\
\hline Lead & 82 & $\begin{array}{l}\text { M- } \\
\text { series }\end{array}$ & 67.24 & 12.39 \\
Oxygen & 8 & $\begin{array}{l}\text { K- } \\
\text { series }\end{array}$ & 17.22 & 41.09 \\
Carbon & 6 & $\begin{array}{l}\text { K- } \\
\text { series } \\
\text { K- } \\
\text { series }\end{array}$ & 13.96 & 44.37 \\
Silicon & 14 & $\begin{array}{l}\text { Total } \\
\text { Ty }\end{array}$ & 100.00 & 100.00 \\
\hline \multicolumn{5}{c}{} \\
\hline
\end{tabular}

\subsubsection{Effect of Initial Concentration of Lead(II) solution and Adsorption Isotherm}

The adsorption capacity of the chitosan/silica composite membrane at optimum $\mathrm{pH}$ and room temperature was studied by varying the initial concentration of lead(II) solution (60, $80,120,140,160,180,200,220$ and 240 $\mathrm{mg} / \mathrm{L})$. The obtained results were plotted in Figure 5. From the data plotted, it was found that the adsorption of metal ions increased with the initial concentration of lead(II) solution. The composite membrane achieved the highest adsorption of lead(II) metal ions at initial concentration of $220 \mathrm{mg} / \mathrm{L}$ with $57.60 \mathrm{mg} / \mathrm{g}$ of adsorption capacity. However, the adsorption capacity of the lead(II) ions decrease at the initial concentration of $240 \mathrm{mg} / \mathrm{L}$. According to the study by Farghali et al. [23], this behaviour is probably due to the increasing of the chemical driving force of concentration gradient. The evaluation on the adsorption mechanism of composite membrane was based on $\mathrm{R}^{2}$ value of Langmuir and Freundlich isotherm model. The Langmuir model assumes that the surface topography was uniform which leading to the monolayer coverage of adsorbate on the adsorbent surface. Thus, no adsorption will take place at equilibrium condition. Meanwhile, Freundlich model assumes that the surface topography was rough and optimum adsorption capacity was achieved when there is no functional group available as active site for adsorption to take place [24]. The results of the experiment of this study were demonstrated in Table 3. As can be seen clearly from the table, the experimental data showed $\mathrm{R}^{2}$ value of Freundlich model was higher than Langmuir model. Thus, the adsorption behaviour that occur between chitosan/silica composite membrane and lead(II) metal ions fitted better with Freundlich isotherm model. This model suggested that the adsorption process happened on the surface of the membrane due to interaction between metal ions and several functional groups of the composite membrane and the process assumed was taking place on heterogenous surface of the membrane with different adsorption energy due to the surface roughness. $[25,26]$

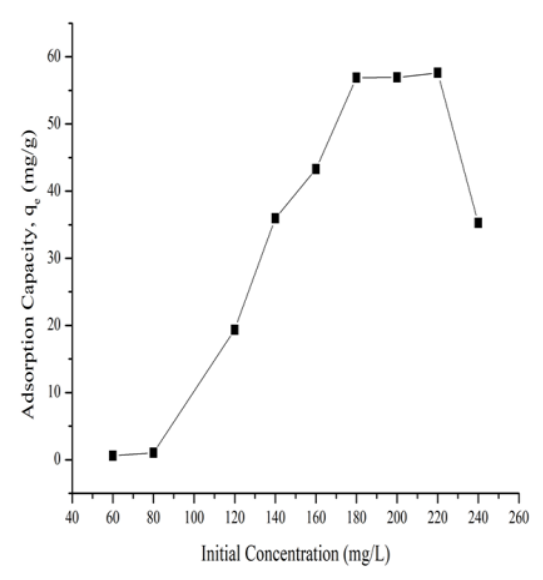

Figure 5 The effect of initial concentration of lead(II) solution

\subsection{CONCLUSION}

In this study, chitosan/silica composite flat sheet membrane was successfully 
Table 3 Langmuir and Freundlich isotherm parameters

\begin{tabular}{lcccccc}
\hline \multirow{2}{*}{ Membrane } & \multicolumn{3}{c}{ Langmuir Model } & \multicolumn{3}{c}{ Freundlich Model } \\
\cline { 2 - 7 } & $\begin{array}{c}\mathbf{Q} \max \\
(\mathbf{m g} / \mathbf{g})\end{array}$ & $\mathbf{b}(\mathbf{L} / \mathbf{m g})$ & $\mathbf{R}^{\mathbf{2}}$ & $\begin{array}{c}\mathbf{K}_{\mathbf{F}} \\
(\mathbf{m g} / \mathbf{g})\end{array}$ & $\mathbf{1} / \mathbf{n}$ & $\mathbf{R}^{\mathbf{2}}$ \\
\hline $\begin{array}{l}\text { Chitosan/silica } \\
\text { membrane }\end{array}$ & -2.3137 & $-5.82 \times 10^{-3}$ & 0.3918 & $1.41 \times 10^{-6}$ & 3.4427 & 0.6449 \\
\hline
\end{tabular}

fabricated via casting technique. The SEM images revealed that the structural properties of pure chitosan membrane can be improved with silica addition. Based on the adsorption study, the removal of lead(II) metal ions have relied on the $\mathrm{pH}$ of lead (II) solution. At optimum $\mathrm{pH}=7.0,89.27 \%$ of lead (II) metal ions removal was achieved. Furthermore, the highest adsorption capacity of $57.60 \mathrm{mg} / \mathrm{g}$ was achieved at initial concentration of $220 \mathrm{mg} / \mathrm{L}$. It is suggested that the adsorption mechanism was following Freundlich isotherm model.

\section{ACKNOWLEDGEMENT}

The authors would like to acknowledge the Universiti Teknologi Malaysia (UTM) under Higher Institution Centres of Excellence (HICoE) grant (Project Number: R.J090301.7846.4J257) and Potential Academic Staff (PAS) grant (Project Number: Q.J130000.2746.02K66) for financially support this research.

\section{REFERENCES}

[1] C. F. Carolin, P. S. Kumar, A. Saravanan, G. J. Joshiba, Mu. Naushad. 2017. Efficient Techniques for the Removal of Toxic Heavy Metals from Aquatic Environment: A Review. J. Environ. Chem. Eng. 5: 27822799.

[2] F. Fu, Q. Wang. 2011. Removal of Heavy Metal Ions from
Wastewaters: A Review. $J$. Environ. Manag. 92: 407-418.

[3] M. A. Barakat. 2011. New Trends in Removing Heavy Metals from Industrial Wastewater. Arabian. J. Chem. 4: 361-377.

[4] S. K. Gunatilake. 2015. Methods of Removing Heavy Metals From Industrial Wastewater. $J$. Multidisciplinary Eng. Sci. Stud. 1: 12-18.

[5] E. Salehi, P. Daraei, A. A. Shamsabadi. 2016. A Review on Chitosan-Based Adsorptive Membranes. Carbohydr. Polym. 152: 419-432.

[6] E. Salehi, S. S. Madaeni, L. Rajabi, V. Vatanpour, A. A. Derakhshan, S. Zinadini, Sh. Ghorabi, H. A. Monfared. 2012. Novel Chitosan/Poly(vinyl) Alcohol Thin Adsorptive Membranes Modified With Amino Functionalized MultiWalled Carbon Nanotubes for $\mathrm{Cu}$ (II) Removal from Water: Preparation, Characterization, Adsorption Kinetics and Thermodynamics. Sep. Purif. Tech. 89: 309-319.

[7] U. Habiba, A. M. Afifi, A. Salleh, B. C. Ang. 2017. Chitosan/(Polyvinyl

Alcohol)/Zeolite Electrospun Composite Nanofibrous Membrane For Adsorption of $\mathrm{Cr}^{6+}, \mathrm{Fe}^{3+}$ and $\mathrm{Ni}^{2+}$. J. Hazard. Mater. 322: 182-194.

[8] M. R. Adam, S. K. Hubaidillah, M. I. M. Esham, M. H. D. Othman, M. A. Rahman, A. F. Ismail, J. Jaafar. 2019. 
Adsorptive Membranes for Heavy Metals Removal from Water In Membrane Separation Principles and Applications From Materials Selection To Mechanisms and Industrial Uses. Edited by A. F. Ismail, M. A. Rahman, M. H. D. Othman and T. Matsuura.

[9] L. S. Rocha, A. Almeida, C. Nunes, B. Henriques, M. A. Coimbra, C. B. Lopes, C. M. Silva, A. C. Duarte, E. Pereira. 2016. Simple and Effective Chitosan Based Films for the Removal of $\mathrm{Hg}$ from Waters: Equilibrium, Kinetic and Ionic Competition. Chem. Eng. J. 300: 217-229.

[10] S. B. Rekik, S. Gassara, J. Bouaziz, A. Deratani, S.Baklouti. 2017. Development and Characterization of Porous Membranes based on Kaolin/Chitosan Composite. Appl. Clay Sci. 143: 1-9.

[11] Y. Rajamoorthy, K. A. Rahim, S. Munusamy. 2015. Rice Industry in Malaysia: Challenges, Policies and Implications. Procedia Econ. Finance. 31: 861-867.

[12] R. Pode. 2016. Potential Applications of Rice Husk Ash Waste from Rice Husk Biomass Power Plant. Renew. Sustainable Energy Rev. 53: 1468-1485.

[13] D. Battegazzore, S. Bocchini, J. Alongi, A. Frache. 2014. Rice Husk as Bio-source of Silica: Preparation and Characterization of PLA-Silica Bio-composites. RSC. Adv. 4: 54703-54712.

[14] E. Vunain, A. K. Mishra, B. B. Mamba. 2016. Dendrimers, Mesoporous Silicas and Chitosan-Based Nanosorbents for the Removal of Heavy-metal Ions: A Review. Int. J. Biol. Macromol. 86: 570-586.
[15] W. Sumarni, R. S. Iswari, P. Marwoto, E. F. Rahayu. 2016. Physical Characteristics of Chitosan-silica Composite of Rice Husk Ash. Mater. Sci. Eng. 107: 1-9.

[16] T. M. Budnyak, I. V. Pylypchuk, V. A. Tertykh, E. S. Yanovska, D. Kolodynska. 2015. Synthesis and Adsorption Properties of Chitosan-silica Nanocomposite Prepared by Sol-gel Method. Nanoscale Res. Lett. 10: 1-10

[17] M. A. Abu-Saied, R. Wycisk, M. M. Abbassy, G. A. El-Naim, F. El-Demerdash, M. E. Youssef, H. Bassuony, P. N. Pintauro. 2017. Sulfated Chitosan/PVA Adsorbent Membrane for Removal of Copper and Nickel Ions from Aqueous SolutionsFabrication and Sorption Studies. Carbohydr. Polym. 165: 149-158.

[18] T. M. Budnyak, V. A. tertykh, E. S. Yanovska, D. Kolodyńska, A. Bartyzel. 2015. Adsorption of $\mathrm{V}(\mathrm{V}), \mathrm{Mo}(\mathrm{VI})$ and $\mathrm{Cr}(\mathrm{VI})$ Oxoanions by Chitosan-silica Composite Synthesized by Mannich Reaction. Adsorption Sci. Tech. 33: 645-657.

[19] F. W. Mahatmanti, Nuryono, Narsito. 2016. Adsorption of $\mathrm{Ca}(\mathrm{II}), \mathrm{Mg}(\mathrm{II}), \mathrm{Zn}$ (II) and $\mathrm{Cd}(\mathrm{II})$ On Chitosan Membrane Blended With Rice Hull Ash Silica and Polyethylene Glycol. Indones, J. Chem. 16: 45-52.

[20] X. He, M. Du, H. Lui, T. Zhou. 2016. Removal of Direct Dyes from Aqueous Solution by Oxidized Starch Cross-linked Chitosan/Silica Hybrid Membrane. Int. J. Biol. Macromol. 82: 174-181.

[21] S. Tasar, F. Kaya, A. Özer. 2014. Biosorption of Lead(II) Ions from Aqueous Solution by Peanut Shells: Equilibrium, Thermodynamic and Kinetic 
Studies. J. Environ. Chem. Eng. 2: 1018-1026.

[22] N. Abdullah, R. J. Gohari, N. Yusof, A. F. Ismail, J. Juhana, W. J. Lau, T. Matsuura. 2016. Polysulfone/Hydrous Ferric Oxide Ultrafiltration Mixed Membrane: Preparation, Characterization and Its Adsorptive Removal of Lead(II) From Aqueous Solution. Chem. Eng. J. 289: 28-37.

[23] A. A. Farghali, M. Bahgat. A. E. Allah, M. H. Khedr. 2013. Adsorption of $\mathrm{Pb}$ (II) Ions from Aqueous Solutions using Copper Oxide Nanostructures. Beni-Suef Uni. J. Basic. Appl. Sci. 2: 61-71.

[24] S. J. Allen, G. Mckay, J. F. Porter. 2004. Adsorption Isotherm Models for Basic Dye Adsorption by Peat in Single and Binary Component Systems. J. Colloid and Interface Sci. 280: 322-333.

[25] N. Abdullah, M. H. Tajuddin, N. Yusof, J. Jaafar, F. Aziz, N. Misdan. 2017. Removal of Lead(II) from Aqueous Solution Using Polyacrylonitrile/Zinc Oxide Activated Carbon Nanofibers. Malays. J. Anal. Sci. 21: 619-626.

[26] U. Habiba, T. A. Siddique, J. J. L. Lee, T. C. Joo, B. C. Ang, A. M. Afifi. 2018. Adsroption Study of Methyl Orange by Chitosan/Polyvinyl

Alcohol/Zeolite Electrospun Composite Nanofibrous Membrane. Carbohydr. Polym. 191: 79-85. 